\section{Thirty-three, zero, nine}

\author{
Caleb R. Matthews, MD, and Phillip J. Hess, MD
}

Thirty-three, 0,9 . Thirty-three, 0,9 . These numbers became a mantra during a long run on a cool spring morning on the Monon trail, or simply The Monon, as it is referred to by most Hoosiers. The Monon is an a familiar path that dissects the heart of Indianapolis, Indiana, connecting the downtown area with more residential boroughs to the north like Broad Ripple and terminating in Carmel, Indiana. The trail is ideal for setting a pace and a location I would typically reserve for longer 10- to 15-mile weekend runs. With virtually no elevation change, straight as an arrow, and no interruption by traffic or crowded sidewalks, it is a predictable, measured quantity and without surprises.

Until recently, my life had been much like The Monon. I had a single trajectory. I never allowed my sidewalks to become too crowded or path too winding. Becoming a cardiothoracic surgeon was my dream since my first step into an operating room as a first-year medical student at the University of Florida where I observed Tom Martin, MD. His reputation preceded him-I had heard stories of him as an educator and aortic specialist but also of his gator hunting escapades. Being from a small rural town in South Georgia myself where activity outdoors is both lifestyle and livelihood, I thought that an interesting juxtaposition. He greeted all learners warmly to his operating room. As if his hands spoke their own language, I recall watching him navigate through the chest with ease and grace amongst the octopus-like heparin coated tubing. A question removed me from my trance: "What rhythm is that?" he asked. Stunned that I was even being acknowledged and wincing at the screen while trying to discern what the rhythm was, I quickly became flushed and sweaty; a feeling that every medical student or resident knows all too well. "Don't look at the screen, look at the heart!" I don't remember what I said, but it wasn't correct. I soon came to learn that the heart had clearly been in ventricular fibrillation. I remember that bag of worms motion like it was yesterday.

\footnotetext{
From the Division of Cardiothoracic Surgery, Department of Surgery, Indiana University, Indianapolis, Ind.

Disclosures: Authors have nothing to disclose with regard to commercial support.

Received for publication Nov 6, 2019; revisions received Nov 6, 2019; accepted for publication Jan 11, 2020; available ahead of print March 30, 2020.

Address for reprints: Caleb R. Matthews, MD, Division of Cardiothoracic Surgery, Department of Surgery, Indiana University, 545 Barnhill Dr, EM Hall, Indianapo-

lis, IN 46202 (E-mail: matthecr@iu.edu).

J Thorac Cardiovasc Surg 2020;160:871-5

$0022-5223 / \$ 36.00$

Copyright (c) 2020 by The American Association for Thoracic Surgery

https://doi.org/10.1016/j.jtcvs.2020.01.092
}

Check for updates

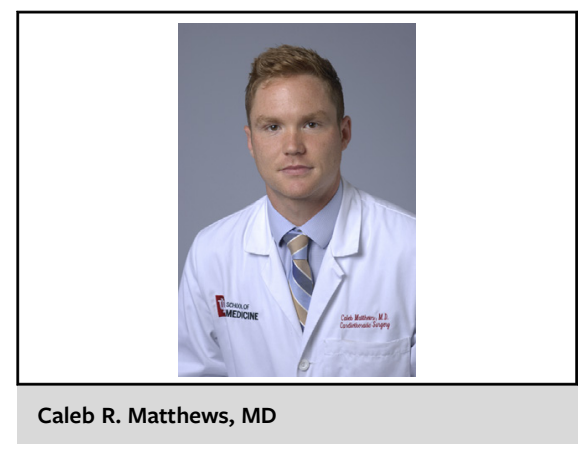

CENTRAL MESSAGE

Disclosing difficult prognosis is an unfortunate obligation all physicians face and is not without consequences. How do we maintain patient autonomy while preserving nonmaleficence?

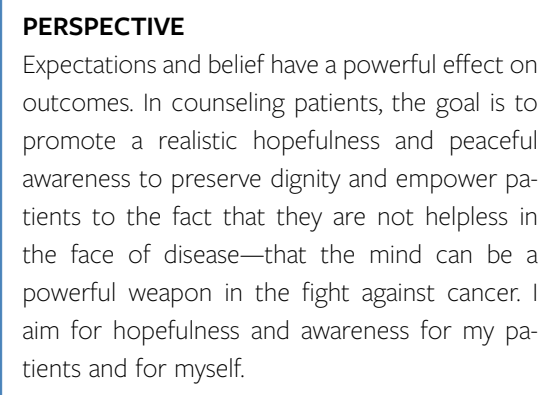

Expectations and belief have a powerful effect on outcomes. In counseling patients, the goal is to promote a realistic hopefulness and peaceful awareness to preserve dignity and empower patients to the fact that they are not helpless in the face of disease-that the mind can be a powerful weapon in the fight against cancer. I aim for hopefulness and awareness for my patients and for myself.

See Commentaries on pages 876,877 , and 878

Despite my less-than-desirable response, he allowed me to close skin. I was hooked.

From Gibbons' account of a patient who experienced pulmonary embolus following cholecystectomy, an inspiration for his work on the heart-lung machine, ${ }^{1}$ to the long feud between Cooley and Debakey, ${ }^{2}$ the beautiful history of cardiothoracic surgery began to reveal itself to me. Later finding out Dr Martin had trained under Debakey and Crawford gave that history a stronger pulse, and I thought of how great it would be to become part of this surgical tradition. Much like ancient lore was propagated by oral tradition, surgical skills seem to have a similar allure and mysticism: Instead of stories, it is the skills and techniques of those who come before you. And in reciprocity they become immortalized through you. I quickly went to the lab, jumped at the opportunity to scrub cases whenever I could, and continued 
to prepare for what I would imagine as a long career in cardiothoracic surgery.

Since I was 4 years old, training has been the centerfold in my life. Physical discipline with focus on my development as a soccer player and my matriculation to a Division 1 collegiate program as well as semiprofessional leagues indeed lent to mental discipline as those lessons shaped my experience through medical school and residency. In fact I ran my first 2 marathons while I was a resident physician; one after a tough call night_-at mile 15 I discovered that was a very poor decision. Despite a rigorous schedule, I continued to build my foundation of endurance, aiming to at 1 point complete a daunting ultramarathon that few are crazy or stupid enough to attempt...33, 0, 9. Thirty-three, 0,9 . Back on The Monon as it offered up its last piece of resistance, I met a stiff gust of wind. Beginning as motivation, the mantra had quickly shifted to a visceral response as my stomach churned. I broke into tears, coughed myself to a near gag, and gasped for air. With just a mile to go on a 10mile excursion, my emotions got the best of me.

I stopped. Regrouped. I had to get home, after all. I continued...

Approaching my 28th birthday, I was in disbelief: The migraines and their increasing complexity weren't just from the stresses of surgical residency. They had become worse with increasing fortification schema, photophobia, and 1 interesting episode of aphasia that led to a few laughs while speaking with a family in the intensive care unit while on call 1 evening. A couple of months later after magnetic resonance imaging scans, multiple small brain lesions were shown to me by an emergency medicine resident physician: a former medical school colleague who conveniently expedited my scan. He opened the door to my room in the emergency department. There was nothing he needed to say that his face didn't already. With a solemn disposition and avoiding eye contact, he revealed the images. "They don't know exactly what this is yet, but it doesn't appear to be good. You have 1 bad thing going for you man, and that's the fact that you're a nice guy."

I was admitted for a full cancer workup thereafter. A computed tomography scan of my chest revealed a $3-\mathrm{cm}$ mass in my left lower lobe with bulky lymphadenopathy, particularly a left hilar node and a subcarinal node. On May 31, 2019, I underwent bronchoscopy with biopsy. I don't think anyone has ever prayed for histoplasmosis, but the night before my procedure I sure did. I decided to switch call shifts with my fellow resident physicians in the intensive care unit because I probably shouldn't work following sedation for bronchoscopy. So I decided to work the night before, and I figured I could at least catch up on sleep with a little help from the propofol. Most of my efforts that week in the surgical/trauma intensive care unit had been taking care of an unfortunate young man who sustained multisystem trauma from a motorcycle accident.
The injury to his brain was too severe to recover from because his constant neurostorming made it more and more difficult to control his intracranial pressures. The family agreed to withdraw support at 2:00 AM. I had the privilege to be a quiet presence in the room. After having been admitted a week earlier with mounting anxiety over the questions the many specialists had about my images, I knew the comfort in having someone with a white coat nearby. I sat silently in the corner of the room as I watched the young man's mean intracranial pressures continue to increase as his family rotated in and out to say their goodbyes. After completing 2 years of residency, I had never pronounced anyone dead. I monitored his pulse as he began to slip away-I felt life slowly leave him. He was 27 years old, the same age as me. As the wee hours of the morning approached the time of my procedure, I couldn't help but feel this coincidence to have an eerie sense of foreboding. That was the last time I worked as a full-time surgical resident.

The biopsy results returned later that week; there was no doubt that it was cancer of neuroendocrine origin, most likely small cell lung cancer (SCLC). The 1-year, 5-year, and median survival for stage IIIB SCLC is $33 \%, 0 \%$, and 9 months, respectively. Thirty-three, 0, 9. At this junction, the brain lesions were considered merely a macguffin as their characteristics were puzzling and likely represented a resolved infection. "Everything happens for a reason." "God has plans for you." Encouraging remarks from well intended loved ones were met with appreciation but inward deflection. I am not much for fatalism. I, like everyone else, am not exempt from the physical forces that dictate the natural world. Assigning meaning or significance to a tragedy can lead to resentment, as the next inclination is to designate responsibility or blame. Despite the surreal nature of my diagnosis given an almost complete lack of risk factors, my having a rare, deadly cancer certainly is not beyond the realm of possibility. Although data from the Surveillance, Epidemiology, and End Results Program indicate that we are at a current downtrend in new cases of lung and bronchial cancer-50.4 new cases per 100,000 persons in 2016, which is the lowest its been since $1975^{3}$-we still have not begun to approach the single digits per 100,000 persons that was seen in the start of the 20th century before the Industrial and Sugar Revolutions, ${ }^{4,5}$ although we are better at screening these days. But an aging population and the height of cigarette smoking in the 1950s cannot alone explain the increase in solid organ malignancies as even childhood malignancies from lymphomas to germcell tumors have increased since the 1970s. ${ }^{6}$ Additionally, the production of synthetic chemicals has risen exponentially since the $1930 \mathrm{~s}^{7}$ a majority of which are carcinogenic. So we are all exposed in 1 way or another. Why? seemed a futile and honestly nonproductive question. Considering the Kubler-Ross 5 stages of grief, I skipped 
denial and took a beeline to anger. I was frustrated not that I had cancer but my life would now be subjugated to a set of numbers. Thirty-three, 0,9 . That anger was quickly replaced by an overwhelming sense of guilt.

I had been in those rooms before, on the other side of the conversation, when my attending came to tell me the news. I had begun making her some tea in an effort to delay the inevitable. She hadn't come directly to my home for no reason. Asking for my family to be in attendance was no empty request. As the kettle began to heat up, so did an odd sense of apprehension, fear, and anticipation. There's little argument that revealing diagnoses and prognoses may be one of the most difficult tasks for a physician. Not to mention the emotional toll, but we are actually pretty bad at prognostication with clinicians often overestimating and only being accurate $20 \%$ to $30 \%$ of the time. ${ }^{9-12}$ I had been asked those questions about prognosis, "How much longer do I have?" As a young physician, I would walk away thinking I did a good job despite leaving patients devastated and in tears. After all, I had gone over the latest data in regard to median, 1-year, and 5-year survival percentages. I was informing the patient. Isn't that the most important thing? Now being presented with the same set of information, I could not help but feel a familiar sense of rebellion. I refused to let those numbers define me. But what about those patients I had interacted with in the past? How dare I leave them with a feeling of an expiration date, like canned food on a shelf? Would they feel condemned by those numbers or motivated? Moreover when does preserving patient autonomy through informed consent violate primum non nocere?

Although prognosis is a key determinant in shared clinical decision making, ${ }^{13}$ revealing it is not without its consequences. Nipp and colleagues ${ }^{14}$ examined quality of life (QOL) following 8 weeks of an incurable gastrointestinal or lung cancer diagnosis. Patients aware of their prognosis had worse QOL, anxiety, and depression. And based on a recent Nationwide Inpatient Sample among breast, lung, prostate, and colon cancer, $11.5 \%$ of cancer patients have major depressive disorders. ${ }^{15}$ Depression itself is linked to worse survival $^{16-18}$ and cancer patients have higher risks of suicide when compared with the general population especially in advanced stages. ${ }^{19,20}$ This fact hits home for me because my aunt took her own life following a relapse in breast cancer. But those patients who did not understand their prognosis well or had misperceptions about the goals of treatment, which is very common ${ }^{21,22}$ reported better QOL and less anxiety. ${ }^{14}$ Similar findings are reported by Sato and colleagues, ${ }^{23}$ where $21.7 \%$ of patients with advanced lung cancer completely misunderstood their prognosis and those who did had higher rates of anxiety and depression. And after multivariate analysis those $21.7 \%$ had less lung specific symptomatic burden. ${ }^{23}$ Ignorance is bliss? Although withholding prognosis can potentially improve QOL, this may have further downstream effects as prognostic awareness in terminally ill patients dictate patient preferred treatment decisions. In a 1998 study by Weeks and colleagues, ${ }^{24}$ of 917 adults with stage III or IV SCLC or colon cancer, patients who believed they were going to live beyond 6 months were more likely to choose life-extending therapy than those who believed they were going to live fewer than 6 months. This has important implications if physicians tend to overestimate.

But maybe the more important question is how much the patient wants revealed? Overwhelmingly patients prefer to know. In fact, $75 \%$ to $91 \%$ of patients want full disclosure and details of their disease process. ${ }^{22,25,26}$ However it's important to inquire as to the level of specificity ${ }^{27,28}$ and that conversation may evolve over time as preferences change. ${ }^{29}$ But I can't help but think that if our prognostication tools are so poor, if expectations can dictate patient specific outcomes, what are we really doing when we share this information? Do we have an opportunity to change perspective, and through changing perspective, can we change someone's biology?

The mind-body connection is one of the most poorly understood relationships today especially in the realm of Westernized medicine. The idea that there's a separation at all may as well be an illusionary construct. Among my favorite quotes from Confucius is, "Those who think they can and those who think they can't are both usually right." Expectations and belief have powerful effects on outcomes. Sir Roger Gilbert Bannister, a British neurologist with a long career in academic medicine, was the first athlete to run a sub-4-minute mile in 1954. Three minutes and 59.4 seconds. Not 46 days later his record was broken. Within the next year, more than 300 runners had run a sub-4-minute mile. ${ }^{30}$ He clearly had broken a mental barrier for athletes around the world, much like Eliud Kipchoge recently did for the sub-2-hour marathon.

What pains me is wondering what had I done to patients' mental barriers by revealing their projected prognoses? Like those who thought the sub-four minute mile was impossible before Bannister, would they also believe that those numbers would dictate their longevity? A worse self-reported outlook on diagnoses is no doubt correlated with decreased survival ${ }^{12}$; even a distress thermometer has been shown to predict 1-year survival in patients with lung cancer. ${ }^{31}$ Some have even posed a cancer-prone personality. ${ }^{32}$ Psychooncology, a relatively new field of medicine, attempts to address the relationship between the mind and cancer-related outcomes. In 1989, among the first investigations of psychosocial counseling in metastatic breast cancer patients was conducted. Those patients who received weekly counseling sessions lived 18 months longer than controls, and this was not explained by disease severity or different treatment pathways. ${ }^{33}$ Along with improved survival, psychological interventions has also been shown to 
reduce relapse in breast cancer patients at 11-year follow-up with improved immune function ${ }^{34,35}$; similar results have been found with patients with bronchial carcinomas as active coping was associated with longer survival. ${ }^{36}$ The culprit believed to be responsible for this effect? The hypothalamic-pituitary-adrenal axis. Although short-term stress has been shown to be immunoprotective, ${ }^{37}$ chronic stress leads to hypothalamic-pituitary-adrenal axis dysregulation, which can lead to abnormal metabolism, increased cortisol levels, and depression. ${ }^{33}$ Increased cortisol has been linked to increased tumor cell turnover ${ }^{38}$ and metastatic spread ${ }^{39}$ in animal models. ${ }^{33}$ Stress's role in survival is further underlined by epinephrine's role in vascular endothelial growth factor signaling increasing blood supply to tumors, ${ }^{40}$ and how the use of $\beta$-blockers has increased disease-free and overall survival in patients with breast cancer. $^{41,42}$ Indeed, there also exists a cytokine-endocrine connection, as patients with cancer have been shown to have an inflammatory cytokine milieu comparable to depressed patients, ${ }^{43}$ and levels of C-reactive protein can predict depression in patients with lung cancer. ${ }^{44}$ Although difficult to characterize the mind-body relationship, there is no doubt it exists. But how does this influence my approach to revealing prognoses? How might I change my practice in the future? How much is really our responsibility as physicians, as the stress response in a given individual is largely out of our control as anxiety is inextricably linked to preexisting personality traits? ${ }^{45}$

"The concept of hope is elusive as we live in a datadriven world." This is a comment from a surgeon while speaking with a patient with recurrent ovarian cancer, 12 years in remission after recurrence, during a discussion at Massachusetts General Hospital in Schwartz Center Rounds in $2007 .{ }^{46}$ I couldn't help but resonate with that statement. I recall in medical school rehearsing breaking bad news in standardized patient scenarios. What I don't recall is counseling hope, something that was missing in those conversations with patients in the past with newly diagnosed cancer. I don't think withholding information about prognosis, although well intentioned, to save someone a stress response is the answer. But how can we promote hope? "Hope is... at one and the same time both an anticipation of something positive and a positive acceptance of the inevitable." ${ }^{46}$ One of my favorite points that David Servan-Schreiber, MD, PhD, makes in his book Anticancer: A New Way of Life (i7 $^{47}$ that most survival curves are right-skewed in their distribution. Although the medians, 1-year, and 5-year survivals for cancers may seem daunting, there are those who are responsible for that long rightward tail. And out on that tail is where I plan on having those future discussions with patients. In the words of the surgeon from Massachusetts General Hospital in Schwartz Center Rounds, "When you approach each patient, you say that there is nothing that says you can't be one of those people who will do incredibly well." ${ }^{46}$ The goal should not be to blind patients in an act of paternalism, but to promote a realistic hopefulness ${ }^{46}$ and peaceful awareness ${ }^{48}$ to preserve patient dignity and empower them to the fact that they are not helpless in the face of disease-that the mind can be a powerful weapon in the fight against cancer.

After 2 cycles of platinum-based chemotherapy and before receiving chest irradiation, my best friend and roommate in medical school convinced me to get a second opinion on my pathology. While sitting at a table full of friends who had flown from all over the country to visit Indianapolis, I received a telephone call from my oncologist on a Friday evening. I think it is a moment we all will forever remember as my oncologist informed me they had changed my diagnosis from SCLC to atypical carcinoid. Thereafter I went for surgical resection that involved bilateral thoracotomies, left lower lobe sleeve lobectomy, lingulectomy, and complete mediastinal lymph node dissection. As if atypical carcinoid weren't rare enough, I unfortunately got right thigh compartment syndrome requiring fasciotomies and 7 additional operations. The overwhelming relief in a less aggressive cancer diagnosis was short lived because follow-up imaging of my brain revealed that those atypical brain lesions had progressed in size and number. Undoubtedly I was stage IV all along. In a personal review of the literature, I have only found 3 to 4 cases of non-SCLS presenting with these specific atypical brain lesions in the past 20 years, none involving atypical carcinoid. The early downstaging may as well have been a blessing in disguise as my systemic disease is currently under control following resection, and the brain is a privileged realm where it can be potentially contained. Despite the looming uncertainty of tomorrow, my hope is to have the honor and privilege to return to training to pay forward to what you, the cardiothoracic surgery community, has bestowed on me in regard to care as a patient and fulfillment as a training physician. I can say with complete confidence that my heart is truly full. Although managing stress as a surgical resident itself may be an act in futility, I aim to at least maintain that state of realistic hopefulness and peaceful awareness for myself and in my approach to those with newly diagnosed cancers. I never again want to leave a patient with the impression that the entirety of his or her life is defined by a set of numbers, like 33, 0,9 .

\section{References}

1. Stoney WS. Evolution of cardiopulmonary bypass. Circulation. 2009;119: 2844-53.

2. Altman L. The feud. The New York Times; November 27, 2007. Available at: https://www.nytimes.com/2007/11/27/health/27docs.html. Accessed March 7, 2020.

3. National Cancer Institute Surveillance, Epidemiology, and End Results Program. Cancer stat facts: Lung and bronchus cancer. Available at: https://seer.cancer. gov/statfacts/html/lungb.html. Accessed February 27, 2020.

4. Spiro SG, Silvestri GA. One hundred years of lung cancer. Am J Respir Crit Care Med. 2005;172:523-9. 
5. Cordain L, Eaton SB, Sebastian A, Mann N, Lindeberg S, Watkins BA, et al. Origins and evolution of the Western diet: health implications for the 21 st century. Am J Clin Nutr. 2005;81:341-54.

6. Steliarova-Foucher E, Stiller C, Kaatsch P, Berrino F, Coebergh JW, Lacour B, et al. Geographical patterns and time trends of cancer incidence and survival among children and adolescents in Europe since the 1970s (the ACCIS project): an epidemiological study. Lancet. 2004;364:2097-105.

7. Davis DL, Magee BH. Cancer and industrial chemical production. Science. 1979; 206:1356. 1358.

8. Markowitz AJ, McPhee SJ. Complexities in prognostication in advanced cancer: "to help them live their lives the way they want to". JAMA. 2003;290:2056.

9. Hui D, Kilgore K, Nguyen L, Hall S, Fajardo J, Cox-Miller TP, et al. The accuracy of probabilistic versus temporal clinician prediction of survival for patients with advanced cancer: a preliminary report. Oncologist. 2011;16:1642-8.

10. Llobera J, Esteva M, Rifa J, Benito E, Terrasa J, Rojas C, et al. Terminal cancer. Duration and prediction of survival time. Eur J Cancer. 2000;36:2036-43.

11. Stockler MR, Tattersall MH, Boyer MJ, Clarke SJ, Beale PJ, Simes RJ. Disarming the guarded prognosis: predicting survival in newly referred patients with incurable cancer. Br J Cancer. 2006;94:208-12.

12. Kao SC, Butow P, Bray V, Clarke SJ, Vardy J. Patient and oncologist estimates of survival in advanced cancer patients. Psychooncology. 2011;20:213-8.

13. Hui D. Prognostication of survival in patients with advanced cancer: predicting the unpredictable? Cancer Control. 2015;22:489-97.

14. Nipp RD, Greer JA, El-Jawahri A, Moran SM, Traeger L, Jacobs JM, et al. Coping and prognostic awareness in patients with advanced cancer. J Clin Oncol. 2017:35:2551-7.

15. Patel RS, Wen KY, Aggarwal R. Demographic pattern and hospitalization outcomes of depression among 2.1 million Americans with four major cancers in the United States. Med Sci (Basel). 2018;6:93.

16. Cash E, Duck CR, Brinkman C, Rebholz W, Albert C, Worthen M, et al. Depressive symptoms and actigraphy-measured circadian disruption predict head and neck cancer survival. Psychooncology. 2018;27:2500-7.

17. Gathinji M, McGirt MJ, Attenello FJ, Chaichana KL, Than K, Olivi A, et al. Association of preoperative depression and survival after resection of malignant brain astrocytoma. Surg Neurol. 2009;71:299-303.

18. Zimmaro LA, Sephton SE, Siwik CJ, Phillips KM, Rebholz WN, Kraemer HC, et al. Depressive symptoms predict head and neck cancer survival: examining plausible behavioral and biological pathways. Cancer. 2018;124:1053-60.

19. Klaassen Z, Wallis CJD, Chandrasekar T, Goldberg H, Sayyid RK, Williams SB, et al. Cancer diagnosis and risk of suicide after accounting for prediagnosis psychiatric care: a matched-cohort study of patients with incident solid-organ malignancies. Cancer. 2019;125:2886-95.

20. Ahn MH, Park S, Lee HB, Ramsey CM, Na R, Kim SO, et al. Suicide in cancer patients within the first year of diagnosis. Psychooncology. 2015;24:601-7.

21. Lobb EA, Butow PN, Kenny DT, Tattersall MH. Communicating prognosis in early breast cancer: do women understand the language used? Med J Aust. 1999;171:290-4.

22. El-Jawahri A, Traeger L, Park ER, Greer JA, Pirl WF, Lennes IT, et al. Associations among prognostic understanding, quality of life, and mood in patients with advanced cancer. Cancer. 2014;120:278-85

23. Sato T, Soejima K, Fujisawa D, Takeuchi M, Arai D, Nakachi I, et al. Prognostic understanding at diagnosis and associated factors in patients with advanced lung cancer and their caregivers. Oncologist. 2018;23:1218-29.

24. Weeks JC, Cook EF, O’Day SJ, Peterson LM, Wenger N, Reding D, et al. Relationship between cancer patients' predictions of prognosis and their treatment preferences. JAMA. 1998;279:1709-14.

25. Miyata H, Takahashi M, Saito T, Tachimori H, Kai I. Disclosure preferences regarding cancer diagnosis and prognosis: to tell or not to tell? J Med Ethics. 2005;31:447-51.

26. Lobb EA, Kenny DT, Butow PN, Tattersall MH. Women's preferences for discussion of prognosis in early breast cancer. Health Expect. 2001;4:48-57.
27. Russell BJ, Ward AM. Deciding what information is necessary: do patient with advanced cancer want to know all the details? Cancer Manag Res. 2011 3:191-9.

28. Gebhardt C, Gorba C, Oechsle K, Vehling S, Koch U, Mehnert A. Breaking bad news to cancer patients: content, communication preferences and psychological distress [Article in German]. Psychother Psychosom Med Psychol. 2017;67: 312-21.

29. Zafar SY, Alexander SC, Weinfurt KP, Schulman KA, Abernethy AP. Decision making and quality of life in the treatment of cancer: a review. Support Care Can cer. 2009; 17:117-27.

30. Hutchinson A. Endure: Mind, Body, and the Curiously Elastic Limits of Human Performance. New York, NY: HarperCollins Publishers; 2018:7-13.

31. Geerse OP, Brandenbarg D, Kerstjens HAM, Berendsen AJ, Duijts SFA, Burger $\mathrm{H}$, et al. The distress thermometer as a prognostic tool for one-year survival among patients with lung cancer. Lung Cancer. 2019;130:101-7.

32. Faller H, Lang H, Schilling S. Causal "cancer personality" attribution-an expression of maladaptive coping with illness? [Article in German]. Z Klin Psychol Psychiatr Psychother. 1996;44:104-16.

33. Spiegel D. Mind matters in cancer survival. Psychooncology. 2012;21:588-93.

34. Andersen BL, Yang HC, Farrar WB, Golden-Kreutz DM, Emery CF, Thornton LM, et al. Psychologic intervention improves survival for breast cancer patients: a randomized clinical trial. Cancer. 2008;113:3450-8.

35. Andersen BL, Thornton LM, Shapiro CL, Farrar WB, Mundy BL, Yang HC, et al Biobehavioral, immune, and health benefits following recurrence for psycholog ical intervention participants. Clin Cancer Res. 2010;16:3270-8.

36. Faller H, Bulzebruck H, Schilling S, Drings P, Lang H. Do psychological factors modify survival of cancer patients? II: results of an empirical study with bronchial carcinoma patients [Article in German]. Psychother Psychosom Med Psychol. 1997;47:206-18.

37. Dhabhar FS. The short-term stress response-mother nature's mechanism for enhancing protection and performance under conditions of threat, challenge and opportunity. Front Neuroendocrinol. 2018;49:175-92.

38. Sapolsky RM, Donnelly TM. Vulnerability to stress-induced tumor growth increases with age in rats: role of glucocorticoids. Endocrinology. 1985; 117:662-6.

39. Ben-Eliyahu S, Yirmiya R, Liebeskind JC, Taylor AN, Gale RP. Stress increase metastatic spread of a mammary tumor in rats: evidence for mediation by the immune system. Brain Behav Immun. 1991;5:193-205.

40. Sood AK, Lutgendorf SK. Stress influences on anoikis. Cancer Prev Res (Phila) 2011;4:481-5.

41. Barron TI, Connolly RM, Sharp L, Bennett K, Visvanathan K. Beta blockers and breast cancer mortality: a population- based study. J Clin Oncol. 2011;29: 2635-44.

42. Melhem-Bertrandt A, Chavez-Macgregor M, Lei X, Brown EN, Lee RT, MericBernstam F, et al. Beta-blocker use is associated with improved relapse-free survival in patients with triple-negative breast cancer. J Clin Oncol. 2011;29:2645-52.

43. Raison CL, Miller AH. Depression in cancer: new developments regarding diagnosis and treatment. Biol Psychiatry. 2003;54:283-94.

44. McFarland DC, Jutagir DR, Rosenfeld B, Pirl W, Miller AH, Breitbart W, et al. Depression and inflammation among epidermal growth factor receptor (EGFR) mutant nonsmall cell lung cancer patients. Psychooncology. 2019;28:1461-9.

45. Shimizu K, Nakaya N, Saito-Nakaya K, Akechi T, Ogawa A, Fujisawa D, et al Personality traits and coping styles explain anxiety in lung cancer patients to a greater extent than other factors. Jpn J Clin Oncol. 2015;45:456-63.

46. Penson RT, Gu F, Harris S, Thiel MM, Lawton N, Fuller AF Jr, et al. Hope Oncologist. 2007; 12:1105-13.

47. Servan-Schreiber D. Anticancer: A New Way of Life. New York, NY: Viking Penguin; 2009:18.

48. Ray A, Block SD, Friedlander RJ, Zhang B, Maciejewski PK, Prigerson HG Peaceful awareness in patients with advanced cancer. J Palliat Med. 2006;9: 1359-68. 